\section{Radio Ambulante e a tradiça
do podcast narrativo no radiojornalismo norte-americano $^{1}$}

\author{
Eduardo Vicente \\ Rosana de Lima Soares
}

\section{Resumo:}

Este artigo apresenta uma discussão sobre podcasts narrativos por meio da análise de Radio Ambulante, programa em língua espanhola criado nos Estados Unidos, em 2011. A pesquisa pretende demonstrar que o surgimento do podcast narrativo está fortemente vinculado à tradição da National Public Radio (NPR), a rede de emissoras públicas norte-americana fundada em 1970. O texto apresenta um pouco da história e exemplos de produções da NPR que se tornaram fundamentais no desenvolvimento da tradição jornalística do podcast. A seguir, destaca o projeto de Radio Ambulante como um dos mais importantes representantes dessa tradição fora do idioma inglês. Na sequência, são analisados dois episódios desse podcast: "Las Hijas de Maria Señorina" e "Mais Médicos”, produções de 2018 que, por serem dedicadas total ou parcialmente ao Brasil, tiveram seus áudios transcritos em português.

Palavras-Chave: Radiojornalismo. Podcasts. Mídias sonoras.

\section{Radio Ambulante and the tradition of narrative podcast in American radio journalism}

\begin{abstract}
:
This paper presents a discussion of narrative podcasts based on the analysis of Radio Ambulante, a Spanish language radio show created in the United States in 2011. The research aims to demonstrate that the emergence of the narrative podcast is strongly linked to the tradition of National Public Radio (NPR), the American public radio network founded in 1970. The article presents a brief history and examples of NPR radio shows that became fundamental in the development of the podcast's journalistic tradition. In addition, it highlights the Radio Ambulante project as one of the most representative examples of this tradition in a foreign language. In this essay, two episodes of this podcast are analyzed: "Las Hijas de Maria Señorina" and "Mais Médicos", productions of 2018 totally or partially dedicated to Brazil that had their audio transcribed in Portuguese.
\end{abstract}

Keywords: Radio journalism. Podcasts. Sound Media.
Recebido em: 08.09.20

Aprovado em: 02.02.21

\section{Eduardo Vicente}

Professor associado na Escola de Comunicações e Artes da USP, com doutorado pela mesma instituição, foi pesquisador visitante na Universidad Complutense de Madrid (Espanha, 2018, Fapesp). É coordenador do Grupo de Estudos e Produção em Mídia Sonora e autor, entre outros, de Da vitrola ao iPod: uma história da indústria fonográfica no Brasil (São Paulo, Alameda, 2014). Bolsista de produtividade em pesquisa do CNPq.

E-mail: eduvicente@usp.br

Rosana de Lima Soares

Professora associada na Escola de Comunicações e Artes da USP, com doutorado pela mesma instituição, foi pesquisadora visitante no King's College London (Inglaterra, 2014, Fapesp). É coordenadora do Grupo de Estudos de Linguagem: Práticas Midiáticas e autora, entre outros, de Sutileza e grosseria da exclusão nas mídias (São Paulo, Alameda/Fapesp, 2019). Bolsista de produtividade em pesquisa do CNPq.

E-mail: rosanasoares@ gmail.com

${ }^{1}$ Versão revista de trabalho apresentado no XXIX Encontro Anual da Compós (UFMS), no Grupo de Trabalho Cultura das Mídias (2020).

Estudos em Jornalismo e Mídia v.18, n.1, jan./jun. 2021.

ISSNe 1984-6924 


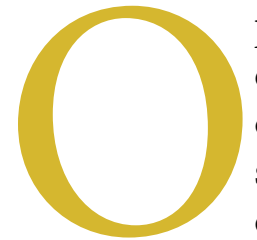

podcast Radio Ambulante foi criado em 2011, nos Estados Unidos, como uma iniciativa voltada para a comunidade latina residente naquele país e para a América Latina em geral. Narrado em espanhol, ele se alinha a uma tradição de programas radiojornalísticos, representada nos Estados Unidos pela National Public Radio (NPR), fundada em 1970, e fortemente presente no universo dos podcasts. Neste artigo, apresentamos alguns exemplos de produções da NPR que se tornaram fundamentais no desenvolvimento da vertente jornalística do podcast, com destaque para This American Life (TAL), criado em 1995. Na sequência, destacamos o projeto Radio Ambulante e analisamos dois de seus episódios: "Las Hijas de Maria Señorina" e "Mais Médicos", ambos de 2018, dedicados total ou parcialmente a questões vinculadas ao Brasil ${ }^{1}$. As análises foram realizadas levando em conta as estratégias narrativas utilizadas nesses gêneros e formatos jornalísticos, apresentadas na primeira parte do texto.

A circulação de podcasts no Brasil atingiu proporções bastante significativas nos últimos anos. Em fevereiro de 2019, a pesquisa Podcast Stats Soundbites colocava o país em segundo lugar no ranking de consumo de podcasts, com 110 milhões de downloads em 2018 - um crescimento de 33\% em relação ao ano anterior -, atrás apenas dos Estados Unidos, com 660 milhões de downloads (BLUBRRY, 2019). Foram várias as produções que se destacaram naquele ano, mas gostaríamos de mencionar aqui duas delas. A primeira é o podcast Vozes: histórias e reflexões (https://audioglobo.globo.com/cbn/podcast/feed/580/vozes-historias-e-reflexoes), produzido e apresentado por Gabriela Vianna, para a rede $C B N$, que conquistou o Prêmio Vladimir Herzog na categoria Produção Jornalística em Áudio (PRESS, 2019). Já O Caso Evandro (https://www.projetohumanos.com.br/temporada/o-caso-evandro), programa produzido e apresentado por Ivan Mizanzuk, entre 2018 e 2019, abordando um caso policial ocorrido no Paraná em 1992, teve seus direitos adquiridos para adaptação como série em vídeo (BRODBECK, 2019).

O que essas produções têm em comum é o fato de poderem ser definidas como "podcasts narrativos", ou seja, podcasts que buscam contar histórias. Esse gênero tem sido, muitas vezes, denominado storytelling, utilizando uma expressão que não é exclusiva de produções sonoras mas diz respeito a um certo modo de criar narrativas roteirizadas por meio de personagens, ações e eventos (ficcionais ou factuais) que possam surpreender e cativar o público de leitores, ouvintes ou espectadores. Vale notar que o storytelling refere-se a uma das estratégias utilizadas na construção de narrativas por meio de palavras, imagens e sons, mas não esgota todas as possibilidades contidas no ato de contar histórias.

Como compreendemos, o conceito de narrativa é definido como mais abrangente que o de storytelling, já que um mesmo enredo pode combinar seus elementos de diferentes maneiras por meio da fabulação nele articulada. A narração - o

${ }^{1}$ Um terceiro episódio, gravado durante a Copa de Futebol Feminino de 2019 no Brasil e divulgado em fevereiro de 2020, conta a

história de uma menina brasileira que sonha em ser jogadora profissional, abordando os preconceitos que ainda cercam essa carreira, narrada pela repórter brasileira Cláudia Jardim e por Irene Caselli. Disponível em: https://radioambulante.org/ audio/laurinha-quiere-jugar.

Acesso em: 8 set. 2020 modo de contar - e o narrador - aquele que conta - tornam-se tão centrais como os personagens ou aquilo que é contado, constituindo a narrativa, "um discurso integrando uma sucessão de acontecimentos de interesse humano na unidade de uma mesma ação" (BREMOND, 1976, p. 118).

Nesse sentido, as duas produções acima citadas diferenciam-se da grande maioria dos podcasts brasileiros que, seguindo formatos radiofônicos mais populares, baseiam-se predominantemente em debates, comentários e/ou entrevistas, simulando a dinâmica de um programa ao vivo. Além do carisma dos/as apresentadores/as ou da pertinência dos conteúdos, muitos desses programas estabelecem vínculos com os ouvintes pela espontaneidade das interações e pelo frescor que essa característica de uma emissão ao vivo - comportando necessariamente um certo grau de improvisação e surpresa - garante. Simultaneamente, eles se baseiam numa fórmula de produção relativamente simples, que permite, em muitos casos, a produção dos programas com pouquíssimos recursos. 
Nenhum desses elementos se aplica aos podcasts narrativos. Essas obras, como veremos, exigem um considerável trabalho de pré-produção, produção e pós-produção através de uma aprofundada pesquisa sobre o tema, captação e gravação de eventos ou entrevistas em diferentes ambientes, obtenção de arquivos sonoros preexistentes, organização e transcrição dos áudios, redação e gravação das narrações que irão conduzir a história, e edição final de um programa que poderá contar, ainda, com músicas, vinhetas e efeitos sonoros variados. Trata-se, no entanto, de uma tendência de produção fundamental no universo dos podcasts, responsável por alguns dos mais importantes e bem-sucedidos programas desse campo de realização audiovisual.

Tomando como base esse cenário, o artigo assume três objetivos fundamentais: apresentar o desenvolvimento da tradição de podcasts narrativos nos Estados Unidos, que situamos no âmbito da NPR; destacar algumas de suas características básicas por meio de exemplos de produções realizadas e de referenciais bibliográficos diversos; e ilustrar seu uso no trabalho desenvolvido por Radio Ambulante. Na conclusão, buscamos aproximar o cenário norte-americano do contexto brasileiro, refletindo sobre a importância de uma melhor compreensão dessa tradição no país, especialmente no meio acadêmico, visando sua aproximação ao universo do jornalismo narrativo e suas derivações.

\section{NPR: radiojornalismo público}

Michael McCauley (2005) aponta que emissoras educativas, muitas delas vinculadas a faculdades e universidades, foram instituições pioneiras do rádio norte-americano. Ainda nos anos 1920, foram concedidas mais de duzentas licenças para essas emissoras, que não só ofereciam espaço para professores ministrarem cursos pelas ondas do rádio, como também uma programação variada, que comportava entretenimento, interesse público e informes voltados para o meio rural (MCCAULEY, 2005, p. 14). Assim, apesar da forte predominância de um modelo comercial, controlado por grandes redes como $C B S$ e $N B C$, é preciso observar que emissoras não-comerciais foram uma presença constante no cenário radiofônico norte-americano desde o seu início.

Um exemplo desse tipo de ativismo foi a criação, nos anos 1940, da Pacifica Radio, uma emissora sustentada com contribuições de seus ouvintes (DUNAWAY, 2017) - prática que, naquele país, iria se tornar fundamental para a sustentação tanto de rádios públicas como de podcasts. A reunião de várias dessas emissoras não-comerciais em uma rede teve seu momento inicial em 1967 com a aprovação, pelo congresso norte-americano, do Public Broadcasting Act, que criou a Corporation for Public Broadcasting, uma organização sem fins lucrativos destinada a receber investimentos públicos e privados para financiar e interconectar essas emissoras (MCCAULEY, 2005, p. 19). Como consequência foram criadas, em 1970, a Public Broacasting System (PBS), voltada para as emissoras de televisão, e a National Public Radio (NPR), que organiza as emissoras em um sistema nacional (Ibid., p. 23). O funcionamento da NPR implicava, em razoável medida, na distribuição de programas em fitas gravadas para posterior veiculação pelas emissoras filiadas. Para tanto, equipes de produção foram formadas e, com o tempo, também produções independentes passaram a ser financiadas e distribuídas.

Gostaríamos de enfatizar a ideia de que essa programação, formada em parte por programas pré-gravados, produzidos por um grupo diversificado de realizadores e não voltados especificamente a um público local ou a questões de interesse mais imediato (as chamadas "notícias quentes"), foi uma característica essencial da NPR. Essa questão nos parece fundamental para que se compreenda o protagonismo que programas da rede terão, posteriormente, no surgimento e consolidação 
dos podcasts narrativos, tributários de uma linhagem radiofônica que buscava, em sua origem, a heterogeneidade e a experimentação.

Como veremos, a NPR esteve aberta, desde o início, à perspectiva de produzir programas inovadores tanto em termos de linguagens como de gêneros. All Things Considered (https://www.npr.org/programs/all-things-considered/), por exemplo, o primeiro grande programa produzido para a rede, já em 1971, era uma revista radiofônica - um formato bastante flexível que comportava a inclusão de noticiário ao vivo, música, poesia, entrevistas, documentários curtos etc. (MCCAULEY, 2005, p. 28-29).

Para Márcia Detoni (2018), All Things Considered, que se mantém até hoje como "o programa jornalístico vespertino mais ouvido do rádio americano (...) abriu espaço para reportagens e peças não ficcionais com muitas sonoras, marcando o renascimento do radiodocumentário no país" (DETONI, 2018, p. 32). A autora aponta como um dos pioneiros dessa tendência o produtor Keith Talbott, que criou, em 1972, a série documental Sound Portrait, incluída na programação de All Things Considered. A série era produzida de forma independente e trazia depoimentos de pessoas comuns sem a intermediação de um entrevistador (Ibid., p. 32), explorando as potencialidades de relatos em primeira pessoa:

No final da década de 1970, a NPR já estava transmitindo uma grande variedade de documentários realizados por sua própria equipe ou por produtores independentes, entre eles Jay Allison, Scott Carrier e a dupla Davia Nelson e Nikki Silva, conhecida como The Kitchen Sisters (as irmãs da cozinha). Os quatro produtores notabilizaram-se, na época, por colocarem no ar histórias contadas por americanos comuns sem comentários de ligação entre as sonoras (DETONI, 2018, p. 33).

Esse aspecto é crucial para compreendermos uma questão central na produção documental, seja em áudio ou em vídeo: a presença ou não do narrador. No trabalho dos realizadores citados por Detoni, a voz do entrevistador, quando existia, era normalmente retirada da edição final, que também não comportava a voz de um narrador ou narradora. Uma vez mais, notamos a presença de elementos literários em formas não-ficcionais, articulando dados factuais às histórias narradas e, de certa forma, ficcionalizando-as por meio de recursos estéticos e estilísticos, a exemplo do que é feito em documentários audiovisuais.

A despeito de sua relevância, a rede enfrentou uma grave crise a partir de 1983 devido aos cortes no financiamento e às pressões econômicas da administração de Ronald Reagan, o que a levou a um perigoso déficit financeiro (MCCAULEY, 205, p. 55). Além de várias ações tomadas para a reestruturação da NPR, é incentivada a produção de programas que aumentem a audiência e o envolvimento dos ouvintes. Dentro dessa nova tradição, em que a figura do narrador passa a ser novamente valorizada, merece destaque This American Life (TAL), de 1995, programa produzido por Ira Glass para a emissora WBEZ 91.5 FM, de Chicago (EUA). Para Detoni, o grande diferencial de TAL é que,

apesar da presença de vários elementos sonoros nas peças produzidas, os relatos são fortemente centrados na narração, retomando a máxima do inglês Laurence Gilliam, criador do Departamento de Especiais da $B B C$, de que "os programas escritos com caneta são melhores que os escritos com o gravador". O script é meticulosamente redigido e elaborado e privilegia a palavra sobre os demais sons. A diferença é que o narrador, agora, se coloca como um contador de histórias. Não tem mais a impessoalidade solene da "voz de Deus", nem a postura objetiva do repórter (DETONI, 2018, p. 37).

Desse modo, ao contrário do que acontecera nas produções documentais pioneiras da rede citadas pela autora, a voz do narrador passa agora a ocupar um papel central. Porém, como aponta Detoni, havia uma importante diferença em relação às produções tradicionais pois, para Ira Glass, os ouvintes 
gostam de histórias que transmitem “a sensação de que o repórter ou apresentador é nosso substituto inteligente e interessante, mostrando ideias interessantes e divertidas, pessoas e perspectivas que nunca ouvimos antes" (MCCAULEY, 2005, p. 128, tradução nossa).

Glass usa o termo "jornalismo narrativo" (narrative journalism) para definir seu programa ${ }^{2}$. Para ele,

as histórias que fazemos são realmente motivadas por personagens, e seguem a mesma estrutura, uma estrutura literária, que uma história de ficção. A história precisa de um personagem, um personagem com o qual você se identifique, que interaja com outros personagens de uma maneira muito específica, e que haja conflito, mudança, resolução (e nem sempre, necessariamente, na parte da resolução) inerente à história, em que os personagens mudam, crescem e aprendem algo novo e surpreendente (ABEL; GLASS, 2012, p. 3, tradução nossa)

A inspiração de Glass no New Journalism é evidente. Combinando elementos literários e jornalísticos, o gênero surgiu nos anos 1960 nos Estados Unidos, buscando introduzir histórias de vida, perspectivas autorais e pontos de vista subjetivos em contraposição às apregoadas objetividade e isenção jornalísticas. Também conhecido, no Brasil, como "jornalismo literário", essa modalidade de narração é bastante presente em grandes reportagens, documentários jornalísticos ou livros reportagem, tradução desse encontro entre literatura e jornalismo:

O jornalismo absorve assim, elementos do fazer literário, mas, camaleão, transforma-os, dá um aproveitamento direcionado a outro fim. (...) E é esta tarefa, a de sair do real para coletar dados e retratá-los, a missão que o jornalismo exige das formas de expressão que passa a importar da literatura adaptando-as, transformando-as (PEREIRA LIMA, 1995, p. 138).

Nessa sua aproximação ao universo literário, de acordo com Detoni, TAL "adota a famosa estrutura dos contos mitológicos e parábolas descrita pelo escritor americano Joseph Campbell como 'a jornada do herói', ou seja, aquela em que os protagonistas enfrentam os obstáculos e descobrem, no processo, uma verdade que é revelada ao mundo no final do relato" (DETONI, 2018, p. 38). Gostaríamos de nos estender mais sobre essa questão.

Em O herói de mil faces (1995), Joseph Campbell aponta a recorrência de certas estruturas simbólicas na constituição de um imaginário reiterado por narrativas que, a despeito de diferenças culturais e históricas, parecem se repetir em relatos contados e recontados em lendas, fábulas e mitos, dos antigos livros às séries e filmes modernos. Mais do que uma aventura desempenhada por um personagem, a "jornada do herói” diz respeito à própria arquitetura narrativa em que, remontando aos conceitos desenvolvidos por Wladimir Propp, em Morfologia do conto maravilhoso (1984), e aplicados ao cinema por Christopher Vogler, em A jornada do escritor (2006), temos um estudo sobre as articulações narrativas "para, ressaltando o papel do narrador, mostrar o papel da própria narrativa em nossas vidas" (GOMES, 2013, p. 1).

Por meio de três atos - a partida, e iniciação e o retorno - Campbell (1995) apresenta uma sequência de estágios percorridos pelo protagonista de uma narrativa até alcançar seu desfecho, passando por desafios, provações, derrotas e conquistas. Antes dele, Propp já havia apresentado as funções presentes nos contos de fada infantis tradicionais e que podem ser percebidas, ainda hoje, nas histórias narradas pela televisão ou pelo cinema. Lugares intercambiáveis ocupados por diferentes personagens, as funções narrativas são, ao mesmo tempo, pontos de estabilização e repetição, e possibilidades de transformação e subversão dessas estruturas, simultaneamente invariantes e mutáveis.

A partir de 2005, This American Life passou a ser distribuído como podcast, acompanhando uma política de maior ocupação do meio digital pelo rádio público que se materializa, em 2003, na criação da plataforma digital Public Radio Exchan-

${ }^{2}$ Disponível em: https:// www.thisamericanlife.org/ about/make-radio. Acesso em: 15 fev. 2020. 
ge (PRX), voltada para a distribuição de áudios. Essas mudanças fariam com que a NPR fosse definida em 2008, pelo jornal The Washington Post, como a maior produtora de podcasts do mundo (FARHI, 2008):

A PRX faz a conexão entre emissoras abertas, produtores independentes e a comunidade, reunindo um extenso catálogo de produções criativas. (...) A PRX é hoje uma das principais distribuidoras de programas para transmissão na rede pública e, em 2014, lançou a plataforma de podcast Radiotopia, uma das mais seguidas do país (DETONI, 2018, p. 39).

Com maior alcance e em formato digital, TAL se aproxima do seu $700^{\circ}$ episódio. Em seu site, define-se como um programa de rádio semanal e um podcast:

A cada semana, escolhemos um tema e reunimos diferentes tipos de histórias sobre esse tema. Fazemos principalmente jornalismo, mas um tipo divertido de jornalismo, construído em torno da trama. Em outras palavras, histórias! Nossos tipos favoritos de histórias têm pessoas atraentes no centro delas, momentos engraçados, grandes sentimentos, reviravoltas surpreendentes na trama e ideias interessantes. Como pequenos filmes para o rádio. Nosso programa é ouvido por 2,2 milhões de ouvintes por semana em mais de 500 estações de rádio públicas nos EUA, com outros 3,6 milhões de pessoas baixando cada episódio como um podcast. Normalmente, somos um dos cinco principais podcasts no iTunes. Também somos ouvidos em estações de rádio na Irlanda e na Alemanha, e em todo o Canadá e Austrália ${ }^{3}$.

Algumas das produções de TAL demandam muito tempo para gravação e edição. Esse foi o caso, por exemplo, do episódio Act V, Scene 1 (https://www.thisamericanlife.org/218/act-v/act-one), de agosto de 2002, que acompanhou por seis meses os ensaios e a apresentação de Hamlet por um grupo de prisioneiros. Por essa razão, a periodicidade semanal de $T A L$ só é possível por meio da atuação de uma grande rede de produtores. Para Detoni, "o sucesso do TAL incentivou vários produtores a relatar histórias reais usando um narrador/contador de histórias. A diferença é que nem todos usam a estrutura da jornada do herói" (DETONI, 2018, p. 38). Entre os programas inspirados por $T A L$ citados pela autora, todos distribuídos ou existindo exclusivamente como podcasts, temos Radiolab (2002), apresentado por Jad Abumrad, que discute temas variados; 99\% Invisible (2012), de Roman Mars, que trata de design, arquitetura e urbanismo; e Invisibilia (2015), de Lulu Miller, Hanna Rosin e Alix Spiegel, que discute as forças que controlam o comportamento humano (Ibid., p. 38).

Mas o mais importante programa inspirado em TAL foi, sem dúvida, Serial (https://serialpodcast.org/season-one), podcast criado em 2014 por Sarah Koenig e que retoma o caso de Adnan Syed, um filho de imigrantes paquistaneses residente em Baltimore (EUA), julgado e condenado pelo assassinato de sua ex-namorada. Koenig dedicou toda uma temporada do podcast ao caso (doze episódios), apontando as inconsistências do julgamento, as falhas da defesa e entrevistando testemunhas, estudantes e policiais. Serial tornou-se o podcast a superar mais rapidamente a marca de 5 milhões de downloads no iTunes (OPAM, 2014) e ganhou os principais prêmios norte-americanos para produções jornalísticas audiovisuais, incluindo duPont-Columbia, Scripps Howard, Edward R. Murrow, e o primeiro prêmio Peabody concedido a um podcast ${ }^{4}$.

Como veremos a seguir, também Radio Ambulante, o podcast do qual ofe-

${ }^{3}$ Disponível em: https:// www.thisamericanlife.org/ about (tradução nossa). Acesso em: 15 fev. 2020.

${ }^{4}$ Disponível em: https:// serialpodcast.org/about. Acesso em: 15 fev. 2020 recemos uma análise mais detalhada, pode certamente ser acrescentado à lista de produções influenciadas pelo modelo narrativo de TAL.

\section{Radio Ambulante e o podcast narrativo}

Surgido em 2011, Radio Ambulante (https://radioambulante.org/) é definido por seus criadores como "um podcast narrativo que conta as histórias da América 
Latina em espanhol. Buscamos levar a estética da boa crônica da imprensa escrita ao rádio. Trabalhamos com uma talentosa comunidade de produtores de rádio, jornalistas e ilustradores de toda a região - incluindo Estados Unidos"'. Daniel Alarcón, escritor e jornalista peruano radicado nos Estados Unidos, é um dos idealizadores do projeto e o apresentador dos programas. Em 2014, Radio Ambulante conquistou o prêmio Gabriel García Márquez na categoria de "Inovação" e, em 2017, o prêmio Third Coast/Richard H. Driehaus na categoria "Melhor documentário em língua estrangeira".

Seguindo uma prática que, como vimos, tem longa tradição no rádio público norte-americano e que se tornaria predominante no universo dos podcasts, Radio Ambulante conta, desde seu início, com o apoio material de seus ouvintes por meio de financiamento coletivo (crowdfunding). Na página do site voltada a essa finalidade, tem opções para doações únicas ou assinaturas (mensais ou anuais) e a lista de benefícios oferecidos aos apoiadores. O ingresso de Radio Ambulante na NPR, em 2016, permitiu que o podcast passasse a ser veiculado também pelas emissoras da rede. O projeto tem buscado formas de interação com os ouvintes e a ampliação do alcance de suas produções. Os clubes de escuta, sua iniciativa mais recente, foram criados em 2018 (SCHMIDT, 2019) e pelo menos um deles reúne mais de 8 mil membros (https://www.facebook.com/groups/clubradioambulante/). Foi criada, também, a Escuela Radio Ambulante, que oferece "um espaço aberto de aprendizagem e colaboração que cobre os princípios básicos do podcasting" "; além do aplicativo de ensino Lupa (https://radioambulante.org/educacion/lupa), voltado a estudantes de espanhol como segunda língua. O podcast também oferece conteúdos extras relacionados aos seus episódios, principalmente textos e vídeos (https:// radioambulante.org/category/extras).

Em 2020, Radio Ambulante chegou à sua 9a temporada, atingindo um total de mais de 160 episódios produzidos ${ }^{7}$. Uma constante no podcast é o fato de contar histórias de toda a América Latina e da comunidade hispânica nos Estados Unidos. A $8^{\text {a }}$ temporada, por exemplo, traz em seus seis primeiros episódios relatos vindos de Colômbia/Costa Rica, México, Porto Rico, Chile, Estados Unidos e Peru, respectivamente. Todos os episódios possuem uma ilustração exclusiva e transcrições completas em, no mínimo, espanhol e inglês. A "comunidade" de profissionais mencionada na apresentação do podcast é um elemento inicial a aproximar Radio Ambulante de TAL: tanto a diversidade temática quanto a periodicidade do podcast são garantidas pela produção simultânea de episódios por diferentes realizadores. De qualquer forma, os programas seguem estruturas de produção muito bem definidas, que garantem sua unidade editorial e sonora, bem como sua qualidade técnica. Denotam, ainda, um cuidadoso trabalho de redação e edição, absolutamente coerente com a tradição da NPR.

Visando ilustrar algumas das características de podcasts narrativos apontadas ao longo do texto, analisamos a seguir dois episódios de Radio Ambulante. $\mathrm{O}$ primeiro é "Las Hijas de Maria Señorina" ("As filhas de Maria Senhorinha”), produzido pela jornalista espanhola Isabel Cadenas e lançado em 13 de fevereiro de 2018 (https://radioambulante.org/transcripcion/traducao-as-filhas-de-maria-senhorinha). Esse foi o primeiro episódio transcrito integralmente para o português e a primeira história de Radio Ambulante sobre o Brasil. O programa tem início, como todos os episódios do podcast, com uma apresentação de Daniel Alarcón: "Bem-vindos à Radio Ambulante na NPR. Eu sou Daniel Alarcón. Hoje começamos com uma notícia...”. A notícia em questão é um vídeo de 2014 do jornal inglês The Telegraph, intitulado Inside the Brazilian all-woman village desperate for men, e relata um fato no mínimo inusitado.

A matéria refere-se ao distrito de Noiva do Cordeiro, no interior de Minas Gerais. No podcast é utilizado o som original do vídeo, em inglês, enquanto Alarcón explica, em espanhol, que a notícia fala de "um lugar no Brasil, habitado ape-

${ }^{5}$ Disponível em: https:// radioambulante.org/sobre-nosotros. Acesso em: 15 fev. 2020.

${ }^{6}$ Ver: https://radioambulante.org/educacion/escuela-radio-ambulante.

${ }^{7} \mathrm{~A} 10^{\mathrm{a}}$ temporada foi lançada em setembro de 2020. Em março, durante a pandemia causada pela Covid-19, foi criado um podcast jornalístico derivado de Radio Ambulante. Chamado El Hilo, o programa é dedicado à cobertura de assuntos importantes para a América Latina e o Caribe e contava, até setembro, com mais de 20 episódios. 
nas por mulheres, todas jovens, todas lindas e todas à procura de marido". Explica também que a "notícia" teria sido veiculada em jornais de todo o mundo. Temos, então, a primeira intervenção de Isabel Cadenas: "E a mesma notícia continua aparecendo até hoje. A última vez que a encontrei foi nas páginas de jornais do Quênia e da Polônia. Mas o começo foi, sim, este vídeo de The Telegraph que dura apenas dois minutos". Alarcón apresenta Isabel, que passa a comentar a reportagem britânica falando de seus sentimentos ao assisti-la: a curiosidade sobre a possível existência de um lugar onde só vivem mulheres no Brasil e, ao mesmo tempo, a revolta com a abordagem "totalmente machista" de todas as matérias que encontrou sobre o tema. Novamente Alarcón narra: "Então, Isabel comprou um bilhete de avião e foi ao Brasil para conhecer este lugar".

\section{Figura 1: página do episódio "Las hijas de Maria Señorina” (2018)}
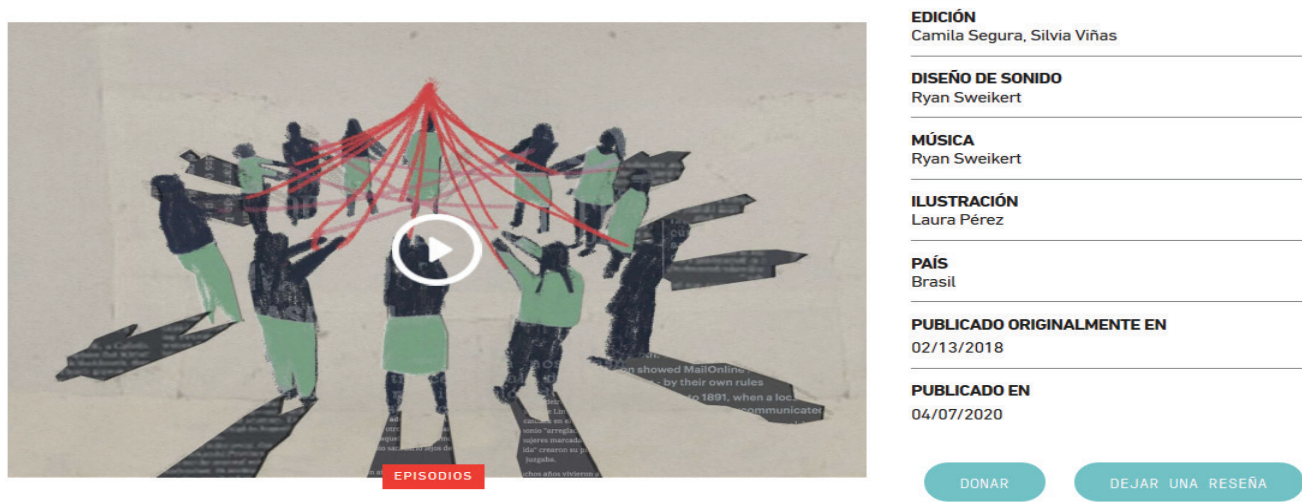

Fonte: Print da tela feito pelos autores

A partir desse momento, a jornalista assume o papel de narradora e protagonista do episódio. Suas intervenções são sempre em primeira pessoa, no local da ação e no tempo presente da narrativa, apresentando suas reações aos fatos na medida em que eles ocorrem. A ênfase em um/a protagonista é constante nas produções de Radio Ambulante e, como vimos, uma característica fundamental dos podcasts narrativos, levando a uma identificação dos ouvintes com os personagens, provocada, também, pelo uso de gravações feitas em externas. Assim, nesses primeiros minutos do episódio temos a fala do comissário de bordo anunciando a chegada do voo a Belo Horizonte; as falas de Flávia e Dario, moradores de Noiva do Cordeiro que irão conduzir a jornalista durante a viagem; e os ruídos e as surpresas de sua chegada à Casa Mãe, espaço comunal onde os habitantes do local (homens e mulheres) se reúnem para apresentações artísticas e para a recepção à repórter.

Essa parte inicial tem como mote principal o espanto da narradora diante de uma comunidade que não se parece em nada com a anunciada na reportagem sensacionalista, mas que, ao mesmo tempo, tem algo de surpreendente e distintivo. $\mathrm{Na}$ sua narração, que tem como fundo o som das apresentações de música e dança na Casa Mãe, Isabel afirma: "E enquanto eles pareciam chegar a alguma coisa parecida com o êxtase, eu não podia parar de me perguntar: onde estou? que lugar é este? E acima de tudo: de onde saiu a história da vila onde só vivem mulheres?". Para em seguida refletir: "Talvez a melhor maneira de responder a isso seja parar. E retroceder um par de séculos à origem da comunidade".

Ouve-se então o ruído característico de uma fita sendo rebobinada, que funciona como uma metáfora dessa volta no tempo. Trata-se de um recurso previsível numa produção ficcional, mas que causa certa surpresa ao ser utilizado numa produção jornalística. A partir desse momento um outro elemento irá se agregar ao programa, reforçando ainda mais a aproximação entre o episódio e a tradição do rádio ficcional: o uso frequente de música de fundo, na forma de uma trilha instrumental. Ela assume uma função estética na obra, mas, mais do que isso, fun- 
ciona frequentemente como um "significante de emoção" (GORBMAN, 1987, p. 73, tradução nossa), enfatizando sentimentos e emoções sugeridos pela narrativa.

No relato que se segue, Isabel retoma a história da comunidade desde seu surgimento, no século XIX. A narrativa é reforçada pelos depoimentos de várias mulheres de Noiva do Cordeiro - todas descendentes em algum grau da fundadora, Maria Senhorinha - e de Pedro, professor na escola local. As falas dos/as entrevistados/as são traduzidas para o espanhol pela repórter. Embora iniciada de forma mais neutra, contando a história da comunidade, essa segunda parte do programa termina de modo bastante emocional, com a afirmação de Pedro de que não se pode entender Noiva do Cordeiro em um áudio ou vídeo, mas apenas "indo lá e sentindo".

A seguir, Isabel, iniciando o que podemos definir como uma terceira parte do episódio, informa que, entre todas as histórias que ouviu em Noiva do Cordeiro, escolheu a de Erick para ilustrar a afirmação de Pedro. A narrativa, fortemente apoiada pela música, mostra como Erick se descobre gay e, preocupado com possíveis reações preconceituosas dentro da comunidade, conta isso a algumas amigas. Elas decidem encenar uma peça de teatro na qual a opção sexual de Erick é revelada à comunidade, que reage de forma compreensiva e acolhedora. Isabel, ao final, ecoa a definição de Pedro sobre a comunidade como sendo formada por "trezentas pessoas em prol da felicidade de apenas uma pessoa" e reforça o caráter extraordinário dessa situação.

A seguir, o episódio retorna, aproximando-se de seu encerramento, ao tema da notícia falsa que lhe serviu de ponto de partida, estabelecendo uma estrutura circular em seu relato. Isso é feito a partir de uma fala de Isabel: "Mas uma vez que entendi como eles vivem, precisava amarrar um pequeno fio solto. Precisava entender como aconteceu e, especialmente, como isso os afetou, no meio de toda essa vida comunitária". Inicialmente, ela retoma esse assunto com Flávia, uma das líderes da comunidade, já conhecida dos ouvintes. A moradora explica que, após a notícia do The Telegraph, de 27 de agosto de 2014, o único telefone do local tocava a noite toda, com pessoas falando em línguas desconhecidas do outro lado da linha. Em seguida, ouvimos a entrevista feita por Isabel com Harry Wallop, o jornalista do The Telegraph responsável pelo vídeo enganoso, traduzida do inglês pela repórter. Embora reconhecendo que a notícia tenha sido exagerada, Wallop defende que se tratava de uma história engraçada e inofensiva, em que ninguém foi prejudicado.

Isabel, evidentemente, não concorda com essa afirmação, mas entende que ela encontra eco nos comentários que recolheu diversas mulheres da comunidade sobre o impacto da notícia - todas as entrevistadas consideram que foi algo positivo, não havendo críticas ou ressentimentos em suas falas. A partir dessa constatação e admitindo sua mudança de percepção sobre o caso, Isabel desenvolve uma reflexão sobre como a origem e a singularidade de Noiva do Cordeiro ajudam a explicar a atitude de suas moradoras diante do ocorrido. Isso traz uma conclusão bastante sensível e, em certa medida, surpreendente para a história, que convidamos os/as leitores/as a conhecer através da audição do episódio. Essa reflexão final da jornalista-narradora ecoa a afirmação de Glass sobre personagens que "mudam, crescem e aprendem algo novo e surpreendente".

Nos créditos finais, são mencionados, além de Isabel Cardenas, os nomes de 14 integrantes da equipe de Radio Ambulante envolvidos na realização. Esses créditos nos ajudam a compreender que, apesar do caráter eminentemente autoral da reportagem, reforçado pela presença da jornalista conduzindo a narrativa ao longo de grande parte dos seus quase 36 minutos, a produção também tem um aspecto coletivo e envolve um grande conjunto de decisões técnicas, estilísticas e estéticas.

No segundo episódio destacado, “Mais Médicos”, de 23 de novembro de 2018 (https://radioambulante.org/audio/mais-medicos), o narrador principal, Alioski Ramirez, é um médico cubano que atuou no Brasil pelo programa "Mais Médicos". Ele é também o protagonista da narrativa, enquanto Daniel Alarcón e a jornalista espanhola Carola Solé (que foi correspondente na Venezuela, México e Brasil) ofe- 
recem elementos contextuais e comentários gerais para suas falas. Alioski nos conta, inicialmente, sobre sua carreira como médico em Cuba, onde começou a trabalhar em 2008, e sobre a perspectiva que sempre acalentou de "sair em missão", ou seja, trabalhar como médico em outros países, por intermédio do governo cubano.

\section{Figura 2: página do episódio "Mais Médicos” (2018)}

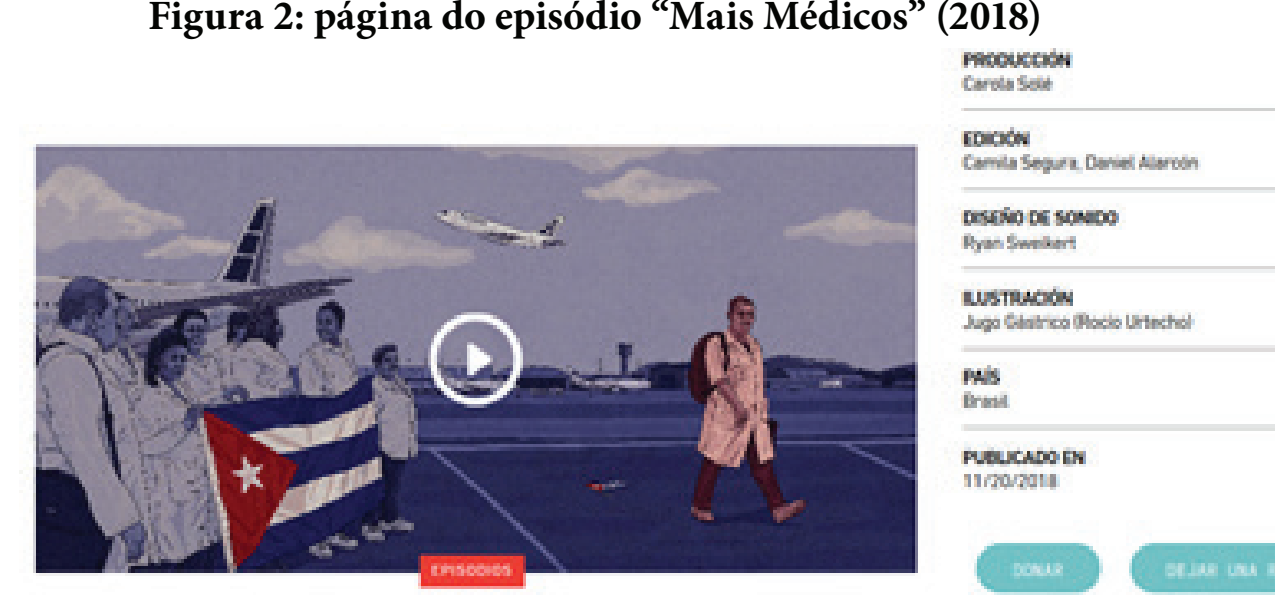

Fonte: Print da tela realizado pelos autores

Temos então gravações de dois trechos de um discurso de Fidel Castro e outras informações (fornecidas por Solé), tanto sobre o começo das missões médicas cubanas no exterior (Argélia, 1963), quanto sobre a importância econômica que estas passaram a ter para o país e para os próprios médicos. Essa descrição encerra o que podemos considerar como a primeira parte do episódio e um breve trecho de um discurso de Hugo Chávez marca o começo da segunda, que traz a descrição da passagem de Alioski pela Venezuela, entre 2011 e 2013. Essa sequência será constituída exclusivamente pelas falas do médico e de Solé. Por meio do relato de Alioski, conhecemos as suas difíceis condições de vida e trabalho na Venezuela, as regras rígidas impostas aos profissionais cubanos no país e sua crescente frustração. É na parte seguinte, a principal do episódio, que será apresentada sua atuação no Brasil.

Esse momento é o mais rico em termos sonoros, pois já em seus minutos iniciais, ele nos traz diversos registros de áudio: o noticiário anunciando a chegada do primeiro grupo de médicos cubanos ao Brasil, em 2013; o discurso da presidenta Dilma Rousseff celebrando o programa; os gritos de protesto de médicos brasileiros dirigidos aos cubanos; o discurso do então deputado Jair Bolsonaro criticando a continuidade do programa após a deposição de Dilma, em 2016; o trecho de entrevista de um dos coordenadores do programa no Ministério da Saúde, naquele mesmo ano; e a fala inicial de Siria, médica cubana que se tornaria companheira de Alioski. Depois disso, há uma predominância das falas do protagonista relatando sua rotina na cidade onde trabalhou (interior de Goiás), e a forma como foi se adaptando e gostando de viver no Brasil.

Em 2017, quarto ano de sua atuação no Brasil, Alioski decide desertar do programa e pedir refúgio político, fato que não é problematizado pelos jornalistas não tanto para evitar um posicionamento sobre a questão, mas sim para manter o foco narrativo no personagem, convocando o público a se posicionar em relação a ele - efeito de sentido construído junto aos ouvintes. Ele torna pública essa decisão em sua página no Facebook. Ouvimos, a seguir, os áudios dos comentários na página, relatos de outros profissionais que tomaram a mesma decisão - nesse caso, em depoimentos extraídos do Youtube -, e a entrevista de uma dessas médicas. Em seguida, temos a gravação em externa de uma visita de Alioski ao seu antigo local de trabalho, meses depois de sua exclusão do Mais Médicos, onde se sobressai a recepção calorosa das enfermeiras. 
Na finalização do episódio, é apresentada a vida de Alioski após a "deserção" e, em sua conclusão, uma fala mais longa de Daniel Alarcón sobre a eleição de Bolsonaro, a saída de Cuba do programa Mais Médicos, em novembro de 2018, e as incertezas em relação ao cenário político e econômico do país. Também nesse episódio, os créditos finais mostram um significativo conjunto de profissionais diretamente envolvidos na realização do programa (seis, no caso), atestando sua sofisticação e abrangência desde a pré-produção até a pós-produção. É importante lembrar que o Brasil, como vimos, não é um país comumente abordado em Radio Ambulante, o que aponta barreiras não apenas linguísticas, mas também culturais e sociais na execução de episódios no país, exigindo da equipe ainda mais dedicação em sua criação e circulação.

\section{Considerações finais}

A intenção deste texto foi oferecer uma reflexão sobre os podcasts narrativos, buscando compreender a tradição radiofônica que ajudou a determinar o seu surgimento nos Estados Unidos. Como o termo passou a ser utilizado de forma consideravelmente frequente no Brasil, tanto por realizadores como no meio acadêmico, consideramos necessária essa reflexão sobre sua origem e inspirações, bem como uma apresentação de suas principais características. Nesse percurso, enfatizamos o papel da National Public Radio e, em particular, do programa This American Life (1995), criado por Ira Glass, como a grande inspiração para os podcasts narrativos atuais.

A fim de demonstrar nossa premissa, destacamos o Radio Ambulante, podcast falado em espanhol, voltado para a América Latina e para a comunidade hispânica dos Estados Unidos e ainda pouco difundido no Brasil (já que o país não está entre aqueles por ele reportados), que consideramos como um dos mais singulares representantes dessa tradição fora do universo anglófono. Por meio dos episódios abordados, tentamos apresentar algumas estratégias narrativas marcantes nesse gênero, sendo a mais importante delas a das histórias "motivadas por personagens", para retomarmos a definição de Ira Glass já apresentada neste texto. Uma das marcas mais significativas do chamado "jornalismo narrativo" que tentamos aqui apresentar diz respeito ao fato de que, sem se furtar a construir um foco discursivo engendrado pelo modo de contar a história, tal proposição seja feita através do ponto de vista de um ou mais personagens, deixando ao ouvinte (ou leitor) a conclusão sobre a história sem que, com isso, seja apregoada uma suposta isenção, neutralidade ou objetividade do jornalista ou da reportagem.

Assim, no primeiro episódio, acompanhamos Isabel Cadenas em sua descoberta de uma comunidade diferente da que esperava encontrar, o que muda radicalmente sua concepção sobre as consequências de uma notícia falsa divulgada para público estrangeiro naquela comunidade no interior do Brasil. É interessante notar que o "tempo da descoberta" da repórter é concebido de modo análogo ao do ouvinte, como se nós e ela estivéssemos presentes sincronicamente na cena, acompanhando suas ações e encontrando, a cada movimento, a sequência espaço-temporal da narrativa. No segundo, conhecemos o médico cubano Alioski e testemunhamos sua crescente frustração ao longo das missões médicas na Venezuela e no Brasil, e que terá como resultado a sua deserção do programa Mais Médicos. Tal desfecho nos traz uma verdade incômoda à medida que somos instruídos, através de recursos sonoros variados que vão construindo, cumulativamente, um efeito de veracidade à ação e, paralelamente, preparando-nos para a decisão radical tomada pelo médico - da complexa situação política, social e econômica não apenas do Brasil (contada por e voltada para a América hispânica), mas também da América Latina.

Esses efeitos de sentido, não apenas narrativos mas também discursivos, não são espontâneos, tampouco naturais em termos narrativos, e sim meticulosamente ensaiados por meio de um processo de montagem em que personagens, lugares e 
cronologias são editados (a exemplo do que vemos comumente no telejornalismo ou em documentários, mas não em programas de áudio) para gerar em nós, ouvintes, tanto a sensação de sermos testemunhas oculares (ou sonoras) das histórias, como também personagens nelas ativos.

$\mathrm{Na}$ descrição dos episódios, portanto, várias características da construção sonora dos podcasts narrativos foram apontadas - como o uso da trilha musical enquanto "significante de emoção", de efeitos sonoros muito próximos à tradição do rádio ficcional, de gravações em externa, de narrações roteirizadas e de um cuidadoso trabalho de edição. Mas, ainda que elas sejam importantes, não devem ser tomadas como definidoras do gênero em si, mas como estratégias para a construção dessas narrativas focadas em personagens e desenvolvidas num claro diálogo com o jornalismo literário.

Tanto em sua concepção quanto em sua materialidade, o podcast narrativo representa um modelo de produção jornalística bastante distinto da tradição brasileira, em que segundo Nivaldo Ferraz e Daniel Gambaro, "valorizamos, no mercado e na academia, a informação em modelo de hard news, com cobertura ao vivo de um lado, e do outro, vozes de especialistas e entrevistas. (...) um rádio essencialmente falado, mas sem a diversidade das vozes" (FERRAZ; GAMBARO, 2020, p. 157-158). Nessa ausência de diversidade, reside também o caráter implicitamente autoritário desse modelo, que acaba limitando a descrição e interpretação das notícias a essas poucas vozes de especialistas, autorizadas e legitimadas pela sua presença no estúdio, processo radicalmente divergente daquele utilizado por Radio Ambulante.

O modelo narrativo aqui apresentado permite, desse modo, um tensionamento de relações de poder tantas vezes presentes na relação entre jornalistas e entrevistados, entrevistadores e fontes, reportagens e narrativas, invertendo os lugares do repórter, do entrevistado e do ouvinte, intercalando seus papeis e tornando-os, ao mesmo tempo, narradores e protagonistas das histórias contadas. Por meio delas, podemos presentificar o passado, acessar o presente e ousar novos voos na criação de narrativas radiofônicas que permitam deslocar o senso comum e mobilizar o sentido de comunidade que, afinal, é o que move nosso desejo de, incansavelmente, contar e recontar histórias.

No percurso apresentado, gostaríamos de destacar ainda o papel desempenhado pelo rádio público como espaço de experimentação e desenvolvimento de novos gêneros radiofônicos. No Brasil, onde um sistema público como o estabelecido nos Estados Unidos ou em diversos países da Europa nunca se consolidou, e a presença do rádio comercial se dá de forma hegemônica, entendemos como fundamental o fortalecimento do papel do meio acadêmico como espaço de discussão e desenvolvimento de práticas radiofônicas transformadoras, participativas e, como

\section{Referências}

ABEL, J.; GLASS, I. Radio: an illustrated guide. Chicago: WBEZ Alliance, 2012.

BLUBRRY. Podcast Stats Soundbite: Brazil in Bloom. Podcast Insider, 01 fev. 2019. Disponível em: https://blubrry.com/podcast-insider/2019/02/01/podcast-stats-soundbite-brazil-bloom/. Acesso em: 15 fev. 2020.

BREMOND, C. A lógica dos possíveis narrativos. In: BARTHES, R. Análise estrutural da narrativa. Petrópolis: Vozes, 1976.

BRODBECK, P. Podcast que conta a história do "Caso Evandro" bate 4 milhões de downloads e vai virar série. G1 Paraná, 15 jun. 2019. Disponível em: https:// g1.globo.com/pr/parana/noticia/2019/06/15/podcast-que-conta-a-historia-do- 
-caso-evandro-bate-4-milhoes-de-downloads-e-vai-virar-serie.ghtml.Acesso em: 15 fev. 2020.

CAMPBELL, J. O herói de mil faces. São Paulo: Pensamento, 1995.

DETONI, M. O documentário no rádio: desenvolvimento histórico e tendências atuais. Pesquisa de Pós-Doutorado. São Paulo: ECA/USP, 2018.

DUNAWAY, D. O documentário radiofônico (entrevista). Novos Olhares. v. 6, n. 1, p. 7-19, jan./jun. 2017.

FARHI, P. NPR Leader Out After Board Clash. The Washington Post, 07 mar. 2008. Disponível em: https://www.washingtonpost.com/wp-dyn/content/article/2008/03/06/AR2008030603473.html. Acesso em: 15 fev. 2020.

FERRAZ, N.; GAMBARO, D. Podcast e radiojornalismo: uma aproximação entre a mídia formal e as novas experiências de produção e escuta. Novos Olhares. v. 9, n. 1, p. 155-172, jan./jun. 2020. Disponível em: https://www.revistas.usp.br/novosolhares/article/view/166393. Acesso em: 31 jan. 2021.

GOMES, M. R. Da narrativa, mais uma vez: transcurso por As Aventuras de Pi. Novos Olhares. v. 2, n. 1, p. 7-16, jul./dez. 2013. Disponível em: https://www.revistas.usp.br/novosolhares/article/view/57036. Acesso em: 15 fev. 2020.

GORBMAN, C. Unheard melodies: narrative film music. London: BFI Publishing, 1987.

MALINE, L. Podcast cresce $21 \%$ no Brasil e Spotify investe em criadores de conteúdo. Techtudo, 01 nov. 2019. Disponível em: https://www.techtudo.com.br/noticias/2019/11/podcast-cresce-21percent-no-brasil-e-spotify-investe-em-criadores-de-conteudo.ghtml. Acesso em: 15 fev. 2019.

MCCAULEY, M. NPR: trials and triumphs of National Public Radio. New York: Columbia University Press, 2005.

OPAM, K. "Serial" breaks iTunes record for fastest podcast to reach 5 million downloads and streams. The Verge, 18 nov. 2014. Disponível em: https://www.theverge.com/2014/11/18/7241715/. Acesso em: 15 fev. 2020.

PRESS. Podcast da CBN vence Prêmio Vladimir Herzog de Anistia e Direitos Humanos. Revista Press, 14 out. 2019. Disponível em: http://revistapress.com.br/revista-press/podcast-da-cbn-vence-premio-vladimir-herzog-de-anistia-e-direitos-humanos. Acesso em: 15 fev. 2020.

PROPP, V. Morfologia do conto maravilhoso. Rio de Janeiro: Forense Universitária, 1984.

SCHMIDT, C. Clubes de escuta da Radio Ambulante criam relacionamentos off-line. IJNET - Rede de Jornalistas Internacionais, 08 out. 2019. Disponível em: https://ijnet.org/pt-br/story/clubes-de-escuta-da-r\%C3\%A1dio-ambulante-criam-relacionamentos-offline. Acesso em: 15 fev. 2020.

VOGLER, C. A jornada do escritor. Estruturas míticas para escritores. Rio de Janeiro: Nova Fronteira, 2006. 